\title{
Usability as a challenge in agricultural engineering
}

\author{
Hannu Haapala ${ }^{1)}$, Piia Nurkka ${ }^{1) 2}$, Kim Kaustel1 ${ }^{1)}$, Tiina Mattila ${ }^{1)}$ and Juha Suutarinen ${ }^{1)}$ \\ 1) MTT Agrifood Research Finland, Agricultural Engineering Research, Vakolantie 55, \\ FI-03400Vihti, Finland, hannu.haapala@mtt.fi, liisa.pesonen@mtt.fi, \\ 2) University of Art and Design Helsinki (UIAH), Hämeentie 135 C, FI-00560 Helsinki, Finland, \\ piia.nurkka@mtt.fi
}

\begin{abstract}
One of the primary goals of research activities has always been to apply the newest potential results into practise. This is the case especially in engineering research. Recently, as productivity has gained importance as a quality measure for research, rapid application of the results has become even more important. Consequently, applicability has been lifted as a major criterion in the application for public funding thus promoting product development as an integrated part of research projects.

No product (or research result) does have any impact if it is not taken into practical use. The end customers of research are supposed to take the developed products into active practical use. Without that phase all our efforts are put in vain.

Usability is an important part of user acceptance. According to Nielsen (1993) system acceptability includes a social and a practical part. To be practically acceptable the product should be e.g. economical, compatible, reliable and useful. To be useful the product should be functionally suitable for the user's tasks and usable. Usability includes easy learn ability, efficiency in use, remember ability, lack of errors in operation and subjective pleasure.

In agricultural research there are distinct problems in usability when considering the phase of taking the results into practical use. Of course, there are challenges also in the initial phase of research such as choosing research topics and later in the initial phase of product development. Usability, however, by far dictates user experience and thus decides if the product is taken into wide use or not.

Consequently, MTT Agricultural Engineering Research has set usability and acceptability research as an important research topic. Usability in agricultural engineering is a complex issue since the context of use is variable. Mobile work is typical to agricultural producers.

In this study, an example of usability evaluation is presented. Mobile work in the context of electronic control of precision combined drilling is evaluated. The research themes were:

1. How great a challenge is usability in Precision Agriculture (PA)?

- is it the cause for poor market penetration?

2. Which usability evaluation methods are applicable to PA?

- are there special issues in PA, or agricultural engineering generally, which limit the feasibility of some methods?

3. Which kind of usability problems can be detected with one selected method (heuristic evaluation)?

- a demonstration of usability evaluation: the Human-Machine Interface (HMI) of a precision combined drill
\end{abstract}

According to literature usability issues have not been a central issue in electronics development in agriculture. Poor experiences of unacceptable operation could be one reason for the customers not relying on new electronic control systems such as those of PA.

There are multiple potential usability evaluation methods for agricultural engineering. The results from the case study performed show that heuristic evaluation is a suitable method for detecting design deficiencies in electronic control of mobile PA. To get a wider picture, further studies with other methods and applications should be done.

Key words: Usability, Acceptability, Agricultural Engineering, Precision Agriculture 


\section{Introduction}

For a long time, engineering in agriculture has been based on quite traditional technologies. Recently new technologies covering the tasks of measurement, control and data management have been introduced. These technologies have been applied in order to enhance the use of traditional technologies. In doing so, accuracy, efficiency and minimised environmental impact have been the goals of the applications. (Rikkonen 2003)

In most cases applications of new technologies on old basic technologies have developed new challenges for agricultural engineers. New measurements have been needed. Controllability of traditional techniques has not been perfect and instrumentation of control systems has not been feasible. Some of the new technologies have been unreliable in agricultural environment. Finally, even though the technical part had been successfully implemented, the new applications have not been taken to wider use by the farmers.

A much discussed topic in connection with the adoption of new appliances has recently been the acceptability and usability of techniques. The cases of mobile telephones and pc software have been most distinct (Hall 2001). Theoretically, usability is considered as a vital part of a wider concept of acceptability (Nielsen 1993). Acceptability is needed in order to introduce any new system into practice.

It can be claimed that, by far, user acceptance is a neglected phase in the agricultural innovation chain. User acceptance is only possible if the end user first knows about the product and its importance for her or him. User benefits should be communicated. The user should have confidence on the promised benefits. A wide market penetration is possible if there are good references and experiences of the use of the product. Good economical result or other valued benefits such as work health or enjoyment are needed.

In agricultural research traditional ergonomics and work health research have mostly included physical issues. Recently, however, new issues such as the HMI (Human Machine Interface) and management have gained in importance.

\section{The challenge of new technology}

New technology poses new challenges to usability research in agriculture. New intelligent layers have been developed between the user and the control system. These layers decide which kind of information is passed on for the user and which part is used for other purposes such as control and reporting (Fig. 1).

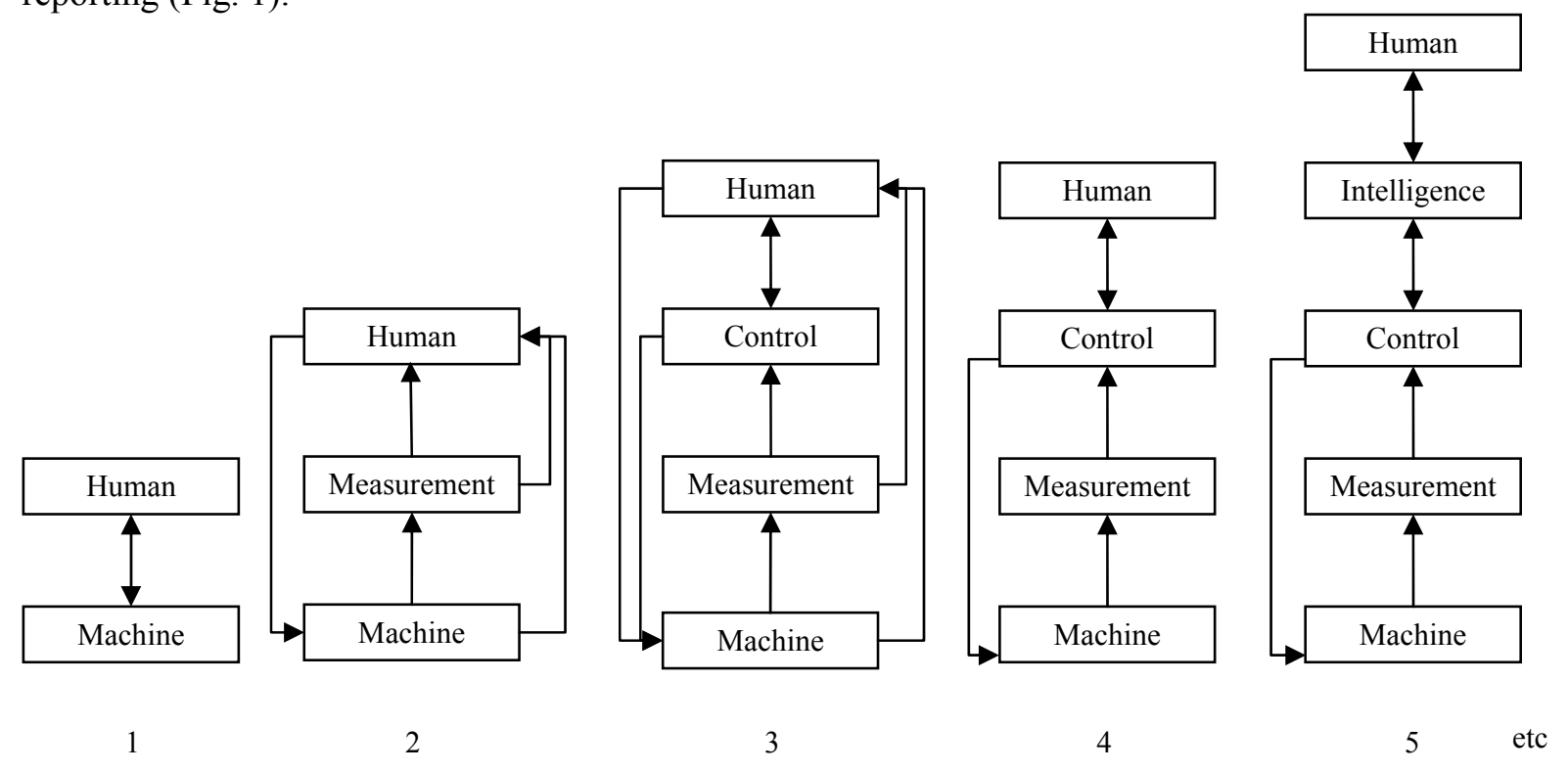

Fig. 1. Development stages of Human-Machine Interface in mobile agricultural engineering (Haapala). 
Because of this development and increase in complexity of work tasks, usability of the equipment becomes more important than before. It is important that the joint system, human and machine together, performs in the intended manner.

\section{Usability and Precision Agriculture}

This paper concentrates on usability issues in PA. Theoretical considerations on usability are presented. A case study of usability evaluation of precision combined drilling is studied. Market penetration of PA has been much poorer than predicted. Therefore it is an interesting question if there could be some problems in user acceptance of this new methodology as a whole. When converting to Precision Agriculture (PA) the task of the user will be changed dramatically since there will be more observation work than before. The equipment will change so that more automation is introduced. This is most distinct in mobile equipment.

Automation is supposed to take responsibility of tasks previously handled manually by the user. The goal is that automation would reduce operator workload and fatigue and increase work efficiency by allowing faster and more precise control of multiple simultaneous tasks (Singh et al.1997). Automation also gives new possibilities for extensive logging of process information which is a central issue in PA. However, if automation is introduced to markets in a very early stage of development it is likely to cause problems for the users and not to improve the situation.

\section{Research themes}

Aim of the study was to concentrate on three research themes:

1. How great a challenge is usability in Precision Agriculture (PA)?

- is it the cause for poor market penetration?

2. Which usability evaluation methods are applicable to PA?

- are there special issues in PA, or agricultural engineering generally, which limit the feasibility of some methods?

3. A demonstration of usability evaluation: the Human-Machine Interface (HMI) of a precision combined drill

- which kind of usability problems can be detected with one selected method?

\section{Material and methods}

Literature was used to unveil the importance of acceptability and usability in agricultural engineering. Usability evaluation methods were selected and a case study on precision combined drilling was performed. The case study demonstrates how usability of agricultural implements can be evaluated.

The need for better usability design in navigation was detected in 1993 in a study in University of Helsinki that dealt with field navigation. (Haapala 1995, Fig. 2).

il.

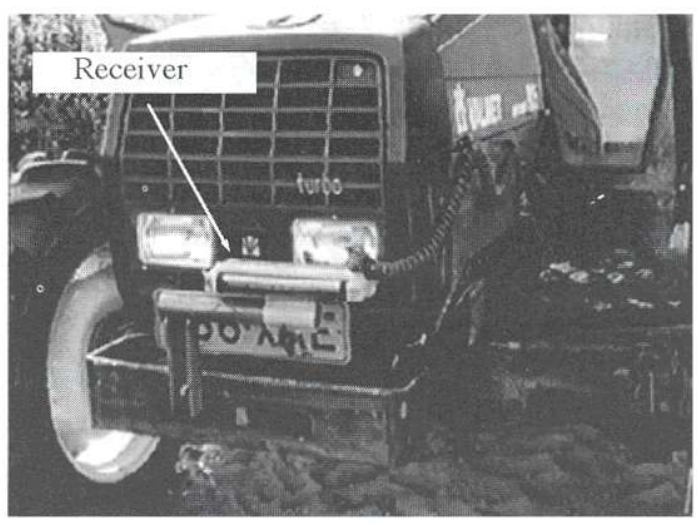

b.

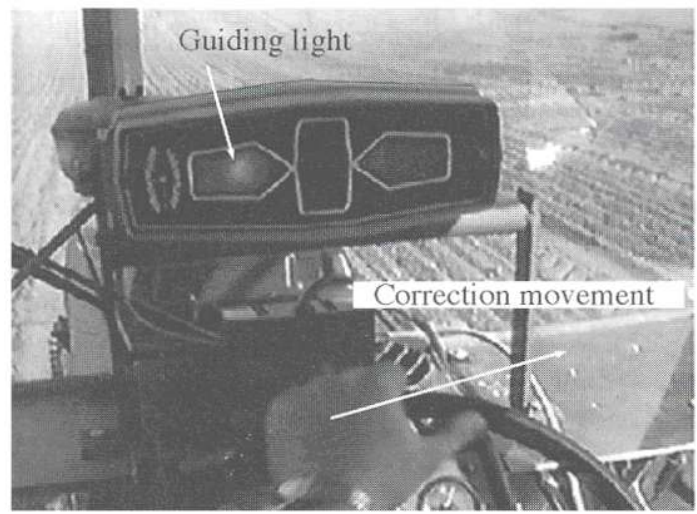

Fig. 2. Field navigation test at the University of Helsinki in 1993. (a) The laser receiver in tractor front. (b) The light bar display in tractor cab. Video captions. (Haapala 1995) 
Actual usability tests were performed later in a more comprehensive automation project named AGRIX that started in 2003 at MTT Agrifood Research Finland. In the latter project a complex ISOBUS based control system with advanced software was under development (Oksanen et al. 2005, Haapala 2005). AGRIX Virtual Terminal software was selected as the target for usability evaluations (Nurkka 2005).

According to MacLeod (2003) the choice of usability research methods has to be adaptive. There is the need to adapt existing usability evaluation methods and develop new ones to help R\&D and user acceptance. As PA is quite a new application for usability designers the design of AGRIX Virtual Terminal software included usability tests with various methods (Nurkka 2005).

A method out of each approach presented in literature was selected for the AGRIX case study, the corresponding methods being interviews of the users (all the implements,) heuristic evaluation (Tume Airmaster ${ }^{\mathrm{TM}}$ combined drill), field observation (Junkkari' ${ }^{\mathrm{TM}}$ sprayer), thinking

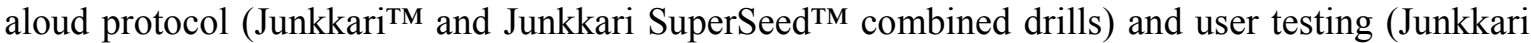
SuperSeed ${ }^{\mathrm{TM}}$ combined drill). Here we present results only of a heuristic evaluation of the combined drill.

The aim was to uncover design and interface deficiencies. The heuristic evaluation proceeded as described in next figure (Fig. 3).

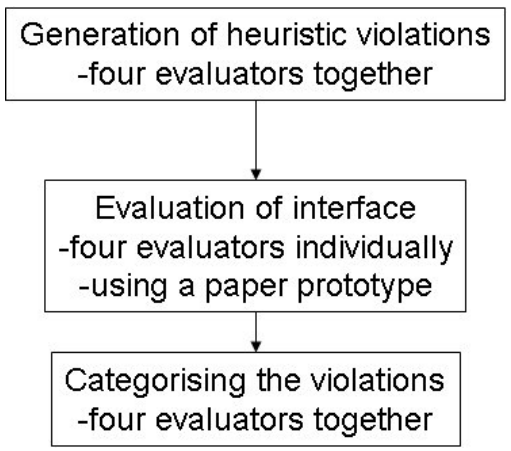

Fig. 3. The sequence of heuristic evaluation.

There were four evaluators who generated a list of heuristic violations based on Jacob Nielsen's list of heuristics (Nielsen 1993). The interface was presented to evaluators as screen shots on paper (paper prototype) with navigation map as a supplement. Evaluation proceeded by the evaluators going through the interface alone first. Then the findings were collected and categorised together according to their severity on the scale 5 to 1 ( 5 catastrophic, 4 poor, 3 acceptable, 2 minor and 1 cosmetic).

\section{Results and evaluation}

Usability as a challenge in Precision Agriculture (PA)

According to ISO 9241-11:1988 standard (ISO 1998): "Usability is the extent to which a product can be used by specified users to achieve specified goals with effectiveness, efficiency and satisfaction in a specified context of use."

Thus, the role of automation should be designed so that automation helps the individual user to simultaneously avoid stress, and increase efficiency of work. Allocation of tasks between the operator and automation should be done carefully to make it possible for the human and machine to collaborate to achieve the operating objectives (Hollnagel 2000). That is why the interaction between the human and machine as well as the work context need to be studied.

According to Nielsen (1993) usability includes several layers whereupon ease of use, efficiency and subjective pleasure are considered as central elements (Fig 4). 


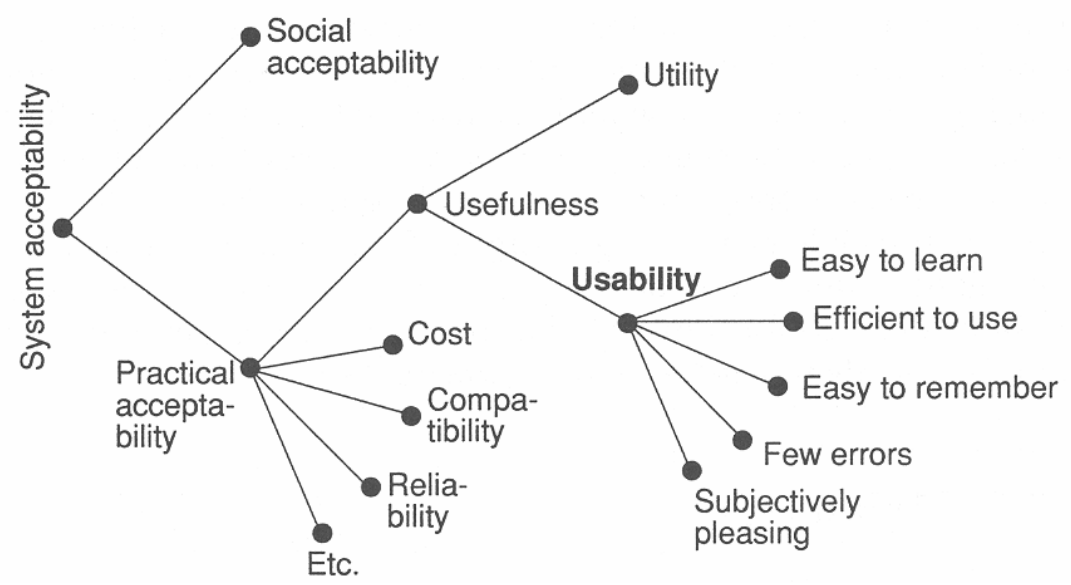

Fig. 4. A model of the attributes of system acceptability (Nielsen 1993).

HMI (Human-Machine Interface) is a central part of usability design. The development of new layers between the user and machine (Fig. 1 above) has put more weight on HMI design. Eventually, the HMI is the only part of the system that the user communicates with. In order to give confidence for the user, the HMI has to be easy to use and reliable. devices:

Dunlop and Brewster (2002) give a list of challenges for usability design of mobile computer

1. Design for mobility

2. Design for widespread population

3. Design for limited input/output facilities

4. Design for (incomplete and varying) context information

5. Design for user multitasking

Kaasinen (2005) concludes that trust is also a very important issue in successful mobile appliances. In order to create trust, the user should feel and really be in control of the work process. Trust is built when the user has a clear conception of the functionality of the appliance even though (s)he does not know all the details. The user also needs to trust on the reliability and accuracy of the information available.

Automation enables the design of complex machine combinations. The combinations can be used for simultaneous tasks not possible for human beings by themselves. However, a complex machine combination is hard to manage even with the help of automation. Automation software design becomes challenging since the number of code lines increases dramatically. Finding errors ('bugs') takes more time and practically it is impossible to simulate all possible user situations and modes of operation. Therefore safety issues also become critical.

\section{Usability evaluation methods of the HMI of a combined drill}

Empirical usability evaluation methods can be divided into three different main categories: usability testing, usability inspection and usability inquiry (Folmer \& Bosch 2004, Nielsen \& Mack 1994). The usability testing approach requires representative users to perform given tasks with the product. The results are assessed to see whether the product supports the user doing the tasks and meets a set of usability criteria. In usability testing the test settings are controlled, so variable factors are eliminated. Usability inspection means examining the product according to established usability principles, e.g. heuristic evaluation, by usability specialists with no real user involvement. Usability inspection takes no consideration on the work environment. The usability inquiry approach aims at detecting information about the users in general and about their interaction with the system in real work settings and context.

In heuristic evaluation of the AGRIX interface altogether 74 violations were found. The largest amount of them, 29 examples, were found relating to the heuristic 'Simple and natural dialogue'. The second highest amount of violations, 10 examples, related on the heuristic 'Speak the users' language'. 
The usability inspection approach (heuristic evaluation) detected issues concerning the information presentation by the user interface of the prototype pointing out the major areas in need of improvement. Observations of violations on heuristics concerning memory load and feedback were inaccurate. This is the case since in the real usage situation the feedback of an action is gained through other senses than visual. However, other senses than visual were impossible to value when using a paper prototype. Consistency as a form of unchangeable navigation logic and function keys should be attained. Shortcuts should be implemented as a form of default values. Error prevention was violated as the AGRIX system does not provide any help. Inconsistency and indistinctness as well as the use of certain icons and language were found to be sources of possible problems in the interaction.

\section{Conclusions}

\section{Usability as a challenge in Precision Agriculture (PA)}

It can be concluded that as new technology, such as PA, is implemented the traditional and adopted ways of interaction between the user and the machine system has to be changed.

Poor user acceptance could be the core reason for Precision Agriculture not being widely adopted in practice. Particularly usability of PA products is not on an acceptable level. In future, usability issues have to be considered carefully when developing successful products for PA. There is a clear need to evaluate the usability of new PA devices to meet the user requirements.

Technically, automation of combined drilling is challenging since there are lots of sensors and actuators needed. Complete automation using ISOBUS allows for new intelligent services for the driver. The usability design, however, is even more challenging. Multitasking situations can not be avoided since during the seeding season farmers are working with multiple simultaneous tasks in their mind. Mobile work in hard environment limits the features of electronics that can be applied.

\section{Usability evaluation methods of the HMI of a combined drill}

Different evaluation methods emphasize diverse dimensions of usability. Thus, in product development, multiple methods for usability evaluation are needed. Development of new agricultural engineering technology should be more user-centred to be able to correspond to all the aspects of usability.

As over half of the problems were found on the areas of simplicity, clarity and appropriateness (heuristics 'Simple and natural dialogue' and 'Speak the users' language'), the conclusion is that more attention has to be pointed at the information presentation and used icons. Only the information needed to carry out a task should be displayed and the information should be presented in logical order. The icons should be designed to symbolize the task at hand and the use of standard icons is advisable.

Usability testing enlightened the users' means of reasoning the way of interaction and the mode of learning. It also pointed out problems related to specific work tasks and functions. Results of the evaluation were promising and proved the potential of the method in the field of software design of agricultural engineering. As the problems were found early in the design process the corrections were still relatively easy to make. User experiences after the improvements proved that the corrections to problems contributed as a better usability of the implement.

The literature and case studies showed that agricultural work is complex and thus the user, the environment, the work practices, the tasks, the equipment etc., have to be taken into consideration to be able to form a comprehensive picture of usability of a product under evaluation. The selection of usability evaluation methods depends on the design phase and thus the expected outcome of the evaluation. 


\section{Literature}

DUNLOP, M. \& BREWSTER, S. 2002. The challenge of mobile devices for human-computer interaction. Personal and Ubiquitous Computing 6: 235-236.

FOLMER, E. AND BOSCH, J. 2004. Architecting for Usability: A survey. The Journal of Systems and Software 7070 (2004) 61-78.

HAAPALA, H. E. S. 1995. Position Dependent Control (PDC) of plant production. Diss. Agricultural Science in Finland 4 (1995): 239-350.

HAAPALA, H. E. S.. 2005. Testing the accuracy of precision combined drilling. Poster abstract: 5th European Conference on Precision Agriculture (ECPA), Implementation of Precision Agriculture. Uppsala 2005, Sweden.

HALL, R. R. 2001. Prototyping for usability of new technology. Int. J. Human- Computer Studies 55: 485-501.

HOLLNAGEL, E. \& BYE, A. 2000. Principles for modelling function allocation. Int. J. HumanComputer Studies 52: 253-265.

ISO 1998. ISO 9241-11:1998. Ergonomic requirements for office work with visual display terminals (VDTs) - Part 11: Guidance on usability. International Standardization Organization. Geneve.

KAASINEN, E. 2005. User acceptance of mobile services - value, ease of use, trust and ease of adoption. Espoo 2005. VTT Publications 566. 151 p. + app. 64 p.

MANNI, J. \& RIIPINEN, T. 2002. Suomalaisen maatalouskoneteollisuuden tulevaisuuden haasteet. Abstract: Future Challenges of Finnish Agricultural Machinery Industry. MTT:n selvityksiä 21. $208 \mathrm{p}$.

McBratney, A., Whelan, B. \& AnCEV, T. 2005. Future Directions of Precision Agriculture. Precision Agriculture 6 (2005): 7-23.

MACLEOD, I. S. 2003. Real-world effectiveness of ergonomic methods. Applied Ergonomics 34: $465-477$.

NIELSEN, J. 1993. Usability Engineering. Academic Press Inc. 362 p.

NIELSEN J. \& MACK, R. L. 1994. Usability Inspection Methods. John Wiley \& Sons, New York, NY.

NURKKA, P. 2005. Study in usability evaluation in the field of agricultural engineering. Poster abstract: 5th European Conference on Precision Agriculture (ECPA), Implementation of Precision Agriculture. Uppsala 2005, Sweden.

OKSANEN, T., SUOMI, P., VISALA, A. \& HAAPALA, H. 2005. ISOBUS compatible implements in the project AGRIX . 5th European Conference on Precision Agriculture (ECPA), Implementation of Precision Agriculture. Uppsala 2005, Sweden.

RIKKONEN, P. 2003. Maatalouden tulevaisuus vuoteen 2025: elintarvikeketjun asiantuntijoiden tulevaisuudenkuvia Suomen maataloudesta. Abstract: Future agriculture in Finland till the year 2025. Future images of agri-food sector experts of Finnish agriculture. MTT:n selvityksiä 32: 51 s. +3 liitettä. http://www.mtt.fi/mtts/pdf/mtts32.pdf

SingH, I. L., MOlloY, R. \& PARASUMARAN, R. 1997. Automation-induced monitoring inefficiency : role of display location. Int . J . Human - Computer Studies 46: 17-30. 